\title{
FORCED CONVECTION HEAT TRANSFER FROM A FLAT PLATE AT DIFFERENT LOCATIONS BETWEEN PLATES ARRAY
}

\section{A. SHALABY}

University of Mansoura

Faculty of Engineering Êl-Mansoura, Egypt.

$$
\begin{aligned}
& \text { - }
\end{aligned}
$$

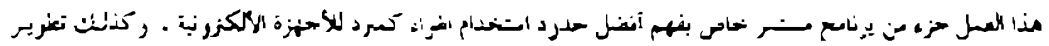

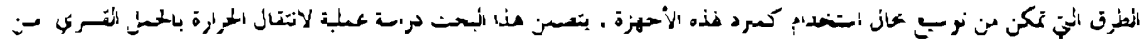

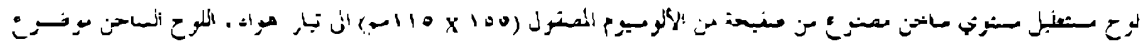

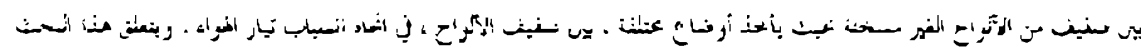

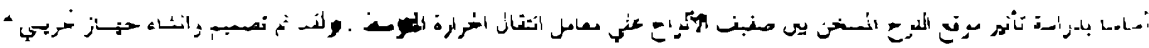

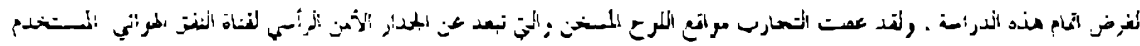

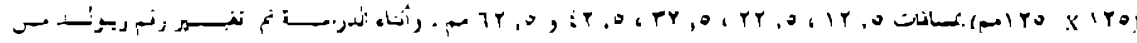

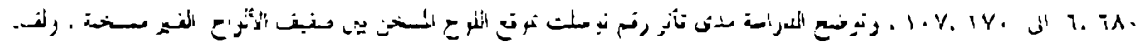

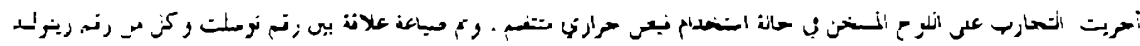

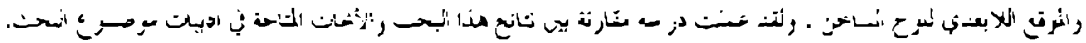

\section{ABSTRACT}

1 forced convection heat transfer experinent was conducted to jtudy the heat transfer from hot rectangular ilat plate (155 x 115 nin) to $2 n$ air strean. The hot plate was situated between unheated plates array at various locations in the rlow direction. The study was mainiy concerned with the effect of the olate location on the werage film rofficient of heat transfer. An experimental test in was designed and constructed for this investigation. The experiments roved the plate locations of $x=12.5,22.5,32.5, i 2.5$ and $0^{2} .5$ inm, and extended over a lanke of Revnolds numijer from about 6,680 lo 107,170. A correlation between the average Nusselt number, the Reynolds number and the hot olate dimensionless location ( $Y$ ) was ledured. The experiments were performed for the case of unilorm had. Plux. A comparison with the available work in the literature review was also made.

\section{INTRODUCTION}

Our previous study [1] on the heat transfer from a flat plate that situated at lifferent localions in the wind tunnel channel presentell a formula for the average Nusselt, number. The flat plate was localded vertically in the direction of air flow stream. The obtained formula loes not indicate that the plate location has a simificant effect on the average heal transfi:r coefficient. The obtained correlation is in the lorm:

$N_{11}=1.97 \mathrm{Pr} 0.33 R^{0.14}$ 
This paper presents the results of a subsequent investigation conducted to establish a formula for the average Vusselt number of the hot plate situated, in the ind tunnel duch, at different locations between number of unheated plates array.

Recent advances in semiconductor technologv have led to increasing miniaturization in circuit design. As electronic components are made smaller, the amount of heat that must be dissipated per unit volume of a device increases dramatically. For example, the peak heat fluxes in a recent comouter circuit are 10 times areater than those in an older computer [2]. Forced convection cooling of the circuitry is commonly used to maintain the desired operating temperature in such a device. The present rork is part of a continuing program to understand better the limits of air cooling, and to develop rethods for extending its usable range. However, in the design of linned heat exchanger surfaces and electronics packages is how to choose the best location of heat generating plates. Several investigalors have attempted to increase the rate of heat transfer in a circuit board 39!. Shalaby, ot. al, (10-12] studied forced convection heat transfer at an inclined and yawed rectangular flat plate. Thes studied the tripping wires ef fect on heat transfer during air flow over the test plate.

The recent reviews of the fundamental heat transfer literature on electronic equipment cooling $[13,14]$ show that the best location and the optinal spacing lave not been determined for packitges linat ure couled by ionced convection. The present study concerned with this problem, and develops concrete means for filling the best location of the heated flat plate situated in a wind tumel chamel letween unheated plates arrav, in the case of laminal flow. The vrubien considered is that of air flow through armat of unheated flat plates located in the wind tunnel duct. The heated flat plate, 115 am $x \quad 055$ $\mathrm{mm}_{1}$ is situated between the flat plates arrav. During the course of the experimental rook the heated olate location thanges to have lateral tistance $(x=12.5,22.5,32.5,+2.5$ and $02.5 \mathrm{man})$ tet.ween it:s center and right inner vertical-wall-face of the liuct. The nind tunim l duct has a squared cross-section of 125 am $125 \mathrm{ma}$.

\section{EXPERIMENTAL APPARATUS AND PROCEDURE}

Ar sxperimental test rip is desianod and inistructod for the planued experiments as shown in Fis.(1). It collsisted ố a iurrurbuience open cilcuit $\boldsymbol{x}$ ind tunnel of 1125 ma square cross section, in wich air from the laboratory room is cilawn through the jvstu uv

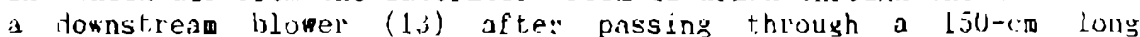
plexiglas entrance section. The rlow rate is controlled liv a throltie valve (15). A flexible textile plastic connection (12) is litteri between the biuwer and the luct to prevent anv ribratinn tramsmission 10 this boury ronis sectron (11), the main duct (b) alud the lost section (8). The velocity of the air strean drawn lhough lhe mail clurt is measured with the help of $r$ itot tube (1B) and an inclined ilohol manometer (19) at the centers of nine imaginary euual areas intu which its plane was divided. The pitol tube is situated 50 r.m upstrean. The air velocity is, also, measured in the hot-wirn inobe(3) located is cm upstream. The iifference in velocity values measurad by the two methods is about $\pm 1.0 \%$. A qeneral lovout of the experinelital apparatus is illustrited in rig. $(1-a)$ with the associated ail supply system and the heating plate. 


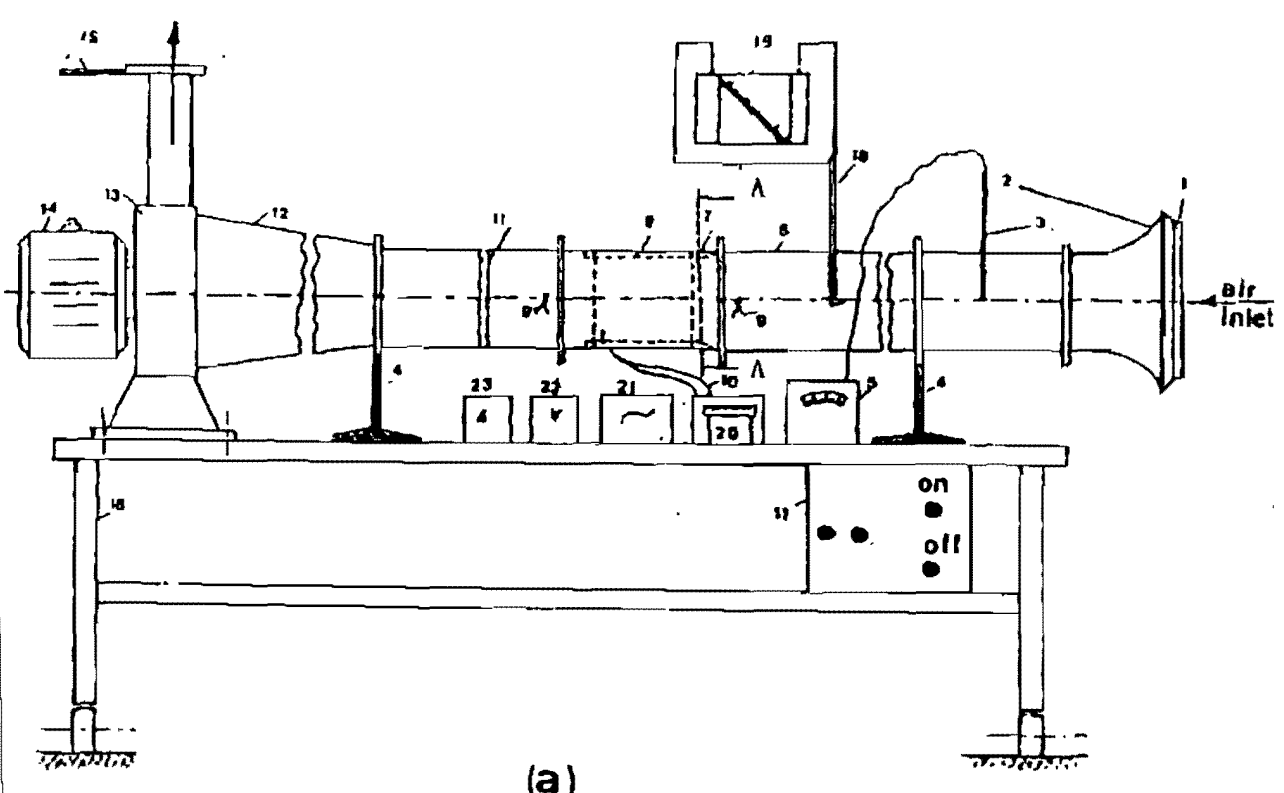

(a)

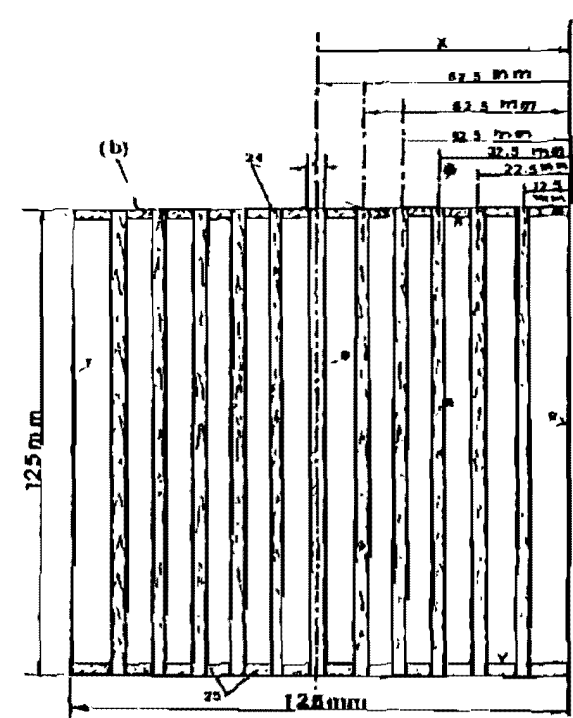

(b)

Section al $A-A$

Fig. (1) Experimental Lesst rik.

1-statilisein plate, 2-colluctor, 3-hut wire anemoncter probe, 4-

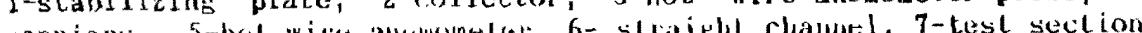
carriers, 5-hol wire antwonelot, 6- shaipht chand, 7-test section channel, 8-lested plate, g-copper-constantan lherwocouple, 10thermocouples comlectivil, Il-honeycual, 12 - connection part, 13- down slream blowe, 1.j-etectrie motor, 15-conlrol discharge gate, 16movable luble, 17-electric panel, 18-rilot tube, 19-inclined mavabie 20-temerature recorder, 21-iulotiansiomer of the lest pliste heater, 22-vullameler, 23-adueler, 24-wooden plates, 25separation weedean s]apus. 
Figure (1-b) shows that the heated test plate (8) is located vertically, between an array of unheated wooden plates (24), in the virection of the main flo stres. The arrav olates are fixed in their locations by the help of mooden slots (25). These slots are iixed on the top and bottom of the wind tunnel channel. The front of the wooden slots has a triangular shape with $15 \mathrm{deg}$, on the horizontal surfaces of the chatinel, to avoid the air disturbance motion near the test plate. Each wooden plate of the array wooden plates has the same outside dimensions of the hot flat plate. The test plate is located far fron the right vertical wall of the wind tunnel channel by five different distances $x=62.5,+2.5,32.5$, 22.5 , and $12.5 \mathrm{~mm}$. The distance between the array plates' center equals $10 \mathrm{~mm}$.

Fig.(2) shows a schematic diagram of the test plate. It has $155 \mathrm{~mm}$ length $115 \mathrm{~mm}$ wicth and $5 \mathrm{~mm}$ thickress. The faces of the test plate are made from two Dolished aluminum sheets ( 1 ), each of them has 1.0 $\mathrm{mm}$ thickness. The lack surface area of each face is divided to $n$ ine iaginary equal rectangular areas, each of $52 \mathrm{~nm}$ lentit! und $38 \mathrm{~mm}$ width approximately. In the center of each area a copper-constantan thermocouple ( 5 ), made from 30 sauge wires, is fixed in thin slots (0.5 $\mathrm{mm}$ deep) cut ois the under side of the plate. The caisbratron of thermocouples was performed and the calibration curve was draw from which, the average of the nine local temperaturus is obtainet. The temperatures are sensed at a depth of about $0.5 \mathrm{~mm}$ from the top polished surface. As such, these values can be taken to repiesent the iuter surface temueratures because of the use of the alumininn viate in which the difference between the estimated outer surfaco lemperatures and the measured values are found to be, in qeneral, less than $0.03 \mathrm{C}$. The plate is heated electinalls b: means of the heater(3), which consisted of nickel-rhromium heating wire wound around a chreaded sheet of aica (1) and sandwiched, also, between, two sheets of mica ( 2 ). Each mica sheet has :j3 mn length, 11,3 mm riuth and $0.5 \mathrm{~mm}$ thickness. The leading edge of the plate is rounded in the direction of flow to avold disturbance in the trailing edge. The average of the nine local temperatures is obtained for each face of the test section plate as follows:

$$
T_{w}=\sum_{n=1}^{9} T_{n} / 9
$$

where $n$ is the location number of the measured point.

The test plate sides are insulated by tinree layers of glass wool tape. On the outer surface of the tade, elght thermoconples are placed and embedded at the mid-height of the surrounding lape (5). The purpose of these thermocouples is to determine the heal loss in. coniuction $\left(O_{\text {cond }}\right)$ from the test plate sides. The mean bulli alr temperatures iar from the tro sides of the plate are measureci usine Lwo novable thermocouples facing each side. .11 the thermocouples arte connected to a six-point-temperature recorder $\left((20)-b_{i 2}\right.$ (1)). The temperature of the duct walls is neasinrell by three thermocouples fixed on the right, left and upper walls af the wind tumel chinnel, at the working section. The ly bulb temperatures at the intiake ot the air blower and at the outlet of the working section are measured.

The neat input to the test plate is controlled br us ins an autotransformer (21) as mell as one roltammeter (22) and ammeter (23), as 


\section{air \\ flow}
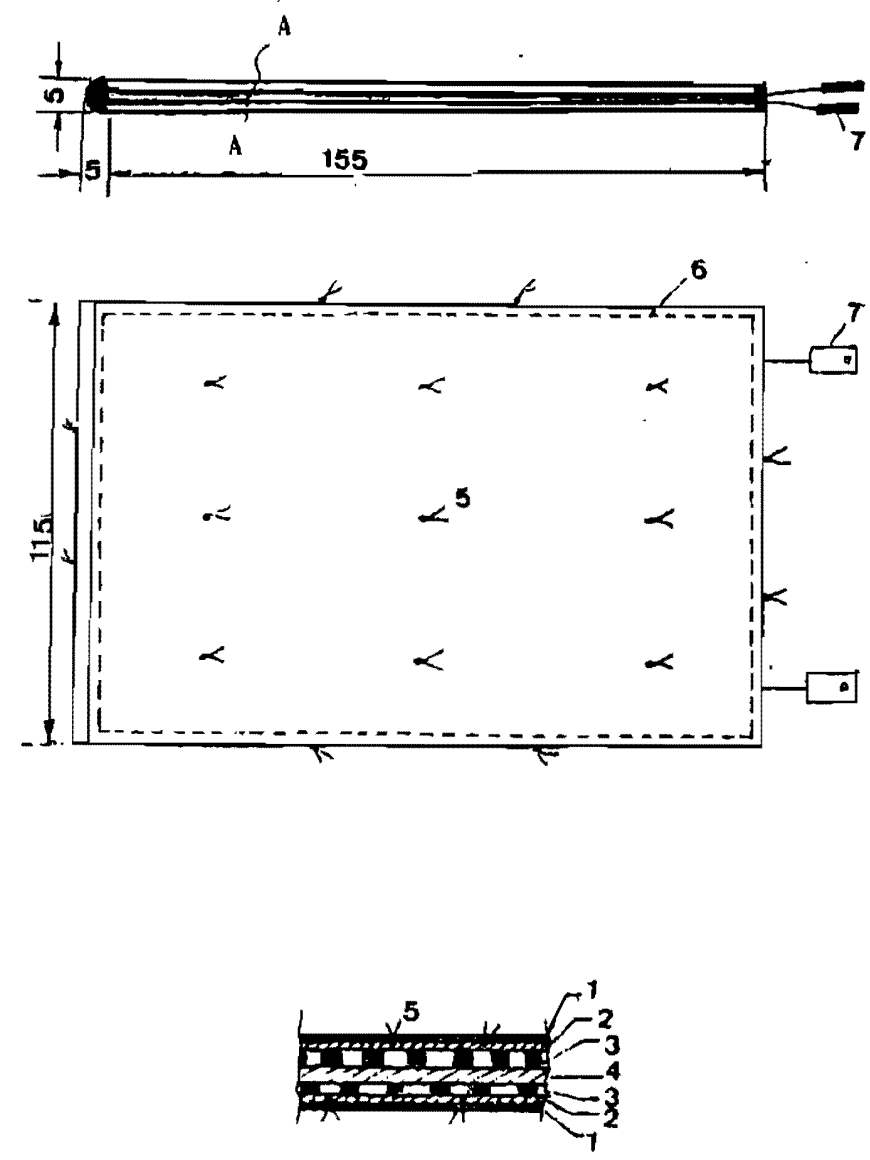

Section at $A-A$

Fig. (2) Construction of the hot plate.

1-two aluminum plates of $1.0 \mathrm{~mm}$ thickness, 2-two plates of mica vith thickness of $0.5 \mathrm{~mm}$, 3-rectangular cross section electric heater, 4-mica plate of $0.5 \mathrm{~mm}$ thickness, 5-copper-constantan thermocouples, 6-glass wool insulation, 7-electric henter connection. 
seen in Fix.(1). Once the switch of the Dower source cloges, the heating system starts. During the course of this experimental mork nearly 2.5 hours are needed to reach the steadv state condition. This condition is satisfied wen the temperature regding does not fecord any change ithin a time period of about 15 minutes. Applying the principle of conservation of energy gives:

$$
Q_{\text {in }}=Q_{\text {cond }}+Q_{\text {conv }}+Q_{\text {rad }}
$$

As the power leads, and the thermocouples ires have verv small cross sections and the various connections in the apparatus are made of insulated materials, then, the awount of heat conducted away through these members is very small and, therefore, can be neglected.

In order to $f$ ind the heat lost bv radiation $\left(0_{\mathrm{rad}}\right)$ the average value of the emissivity of 0.24 for polished aluminium plate was raken from $[15,16]$, in which thev reported that no simnificant clependence of emissivity on remperature as observed. The estimated values of Qcond and those of Orad mere of order 15 to $35 \%$ of the input power to the hot vlate heater. The average convective heat transfer coefficient is determined from the following expression;

$$
h=\left(Q_{\text {in }}-Q_{\text {cond }}-Q_{\text {rad }}\right) /\left(A\left(T_{w}-T_{a}\right)\right\}
$$

The probable error in finding the average heat transfer coefficient as estimated to be about $\pm 7 x$. The pro.jected area of the test plate on a vertical plane verpendicular to the tunnel axis equals the cross-sectional area of the test plate (the plate width $x$ the plate thickness\}. It is found that if the blockase of the wind tunnel free stream cross-section area is about 10\%, Test and Lessmann[1j] have reported that the ir heat transfer results with and without blockage differ by a maximum of $i x$. In the present work the blockage of the wind tunnel iree stream cross-section area is aboul: 44\%. Therefore, the blockage mav affect the heat transter resilits to some extent.

\section{RESULTS AND DISCUSSION}

In order to find the average heat transfer coefficients and their correlation with air flow, some quantities are measured for each dala run. The power input to the test plate heater, the rate of heat lust by radiation from the plate surfaces to the wind tunnel channel wals, the heat lost by cunductiun from the test olate sicies. the average flat plate surface temperature, the air flow stieam velocity and the iree stream temperature are recorded. The liet rate of heat transfer by convection is used to calculate the average heat transl'er coefficieut from equation ( 4 ). The characteristic length used in both Visselt numbel and Reynolds number is the rest plate length ( $L$ ). The air density is taken at the bulk temberature, while the uther properties are taken at the mean film temperature.

The varaneters that are varied independentiy during the course of experiments included the main air stream velocity (or Re) and the test plate location ( $x$ ). The Revnolds number spanned the "ange" lotisee! 6,680 and 107,170 and the values of $x$ chosen ale $12.5,22.5$, $32.5,12.5$ and $62.5 \mathrm{~mm}$. The results for different locations could be represented by equation (5) and Table (1) as follows:

$N u=c R e^{m}$ 
where $c$ and $m$ are constants shown ill Table (1).

Table (1): Values of the constants of heat transfer equation (j)

\begin{tabular}{|c|c|c|}
\hline \multirow{2}{*}{$\begin{array}{c}\text { Plate location } \\
\text { ( } x \text { ) } \\
\text { in } \mathrm{mm}\end{array}$} & \multicolumn{2}{|c|}{ Values of the constants } \\
\hline & $c$ & $\mathbb{w}$ \\
\hline $\begin{array}{l}12.5 \\
22.5 \\
32.5 \\
42.5 \\
62.5\end{array}$ & $\begin{array}{l}0.372 \\
0.428 \\
0.469 \\
0.501 \\
0.573\end{array}$ & $\begin{array}{l}0.58 \\
0.56 \\
0.55 \\
0.54 \\
0.53\end{array}$ \\
\hline
\end{tabular}

The results of different plate locations are plotted in the form of Nusselt number versus Reynolds number, as shown in Fig. (3-i). Euch figure is drawn at a certain value of $x$. The figures, also, have the dashed line obtained from correlation (1) as well as the solid line obtained from the following correlation[17];

$N_{u}=0.6795 \mathrm{Pr}^{0.0 .33} \mathrm{Re}^{0.5}$

Where $\operatorname{Re} \leq 3 \times 10^{5}$

This correlation has been obtained bv usine integral method in the case of laminar heat transfer and with a constant-lieat flux from the test plate surface.

Results of fiu values versus Re, in case of $x=12.5 \mathrm{~mm}$, are shown in Fig.(3), Generally, one car: see that Nu value increases ith Re. Also, it can be observed that, the vu values obtained from the present experimental work are, generally, higher than the solid line ot equation (6) and less than the dashed line of equation (1). This may lse because of the blockage effect. It is also seen that the slop of the present results line is higher than the slops of the two lines obtained by equations (1) and (6). The phesent data show some approach with the same obtained bv equation (6) at law Re values and show a quite good approach with the data obtained by equation (1) at high Re ralues. This mar be because in the case of air flow through a recrangular duct (like the air flow through the plates array) the coefficient of friction decreases with the increase of Revnolds uumiser [18].

Results of the Nu values versus Re values in the case of $x$ equals $22.5,32.5,42.5$ and $62.5 \mathrm{~mm}$, are illustrated in Figs. $(4,5,6$ and 7) respectively. The main observation, comes out of these four figures, is the slop of the Nu values versus Re values decrease with the increase of $x$, i.e. as the test plate location moves far from vertical channel wall. This may be because of the shape of the air flow velocity profile at the olates array cntrance. In the case of fully leveloped laminar flow, the air velocity value increases with $x$ to have the maximum value at the duct center.

In a 11, 132 data points obtained axe represented in Fig. (8). One may clearly observe that, the Nu values, generally, increases with Re. The data shows a dependence on the test plate location $(x)$. Along 


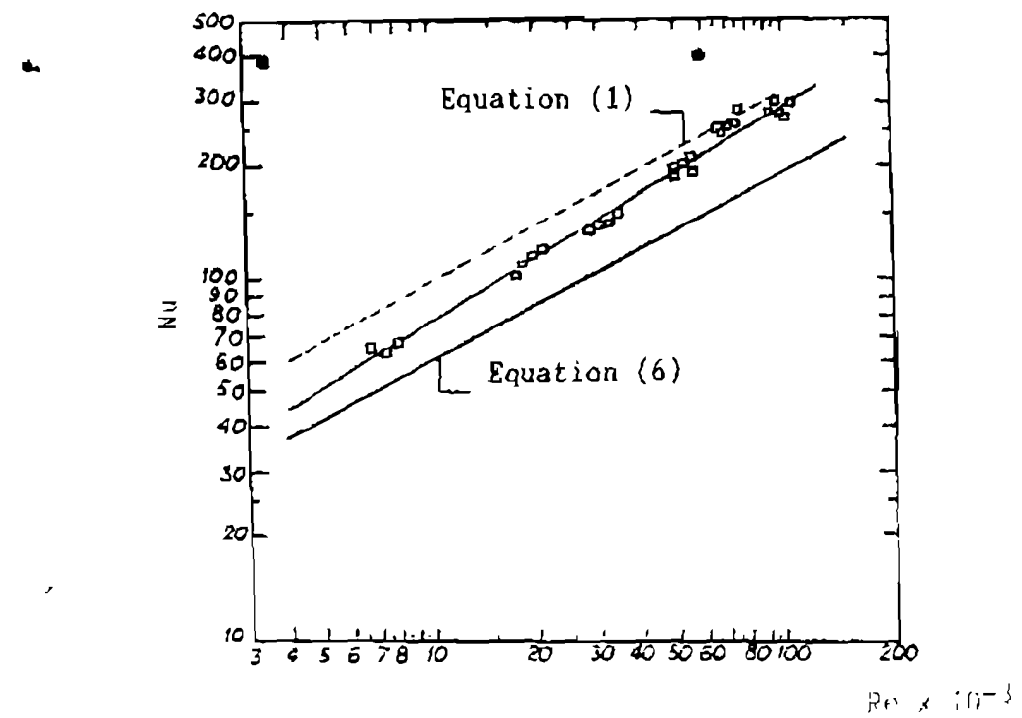

Fig. (3) Average Vusselt number versus Reynolds number , at $x=12.5 \mathrm{~mm}$.

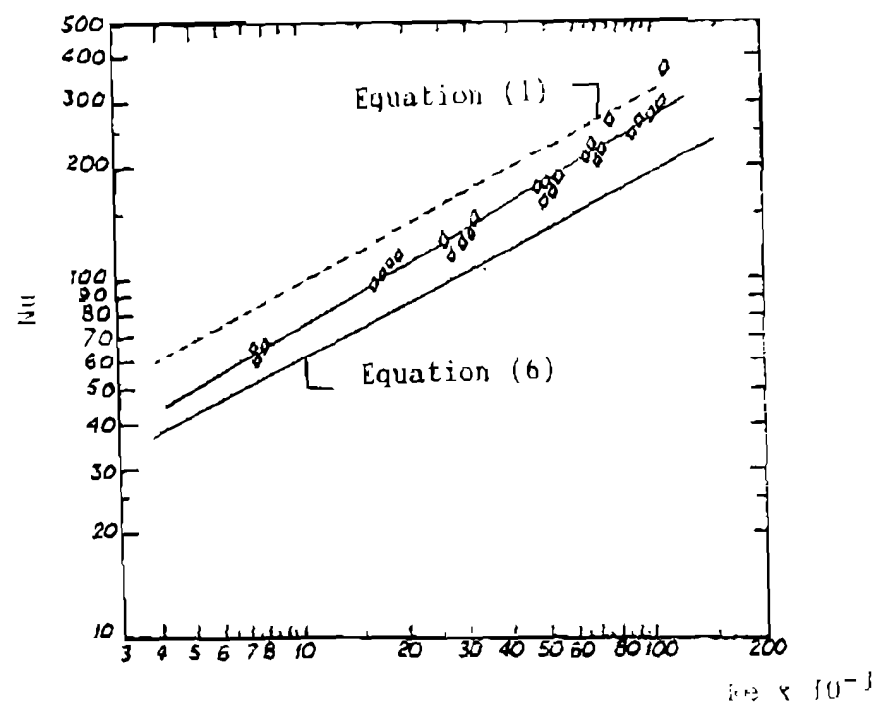

Fig. (4) Average vusselt number versus Reynolels number, at $x=22.5 \mathrm{~mm}$. 


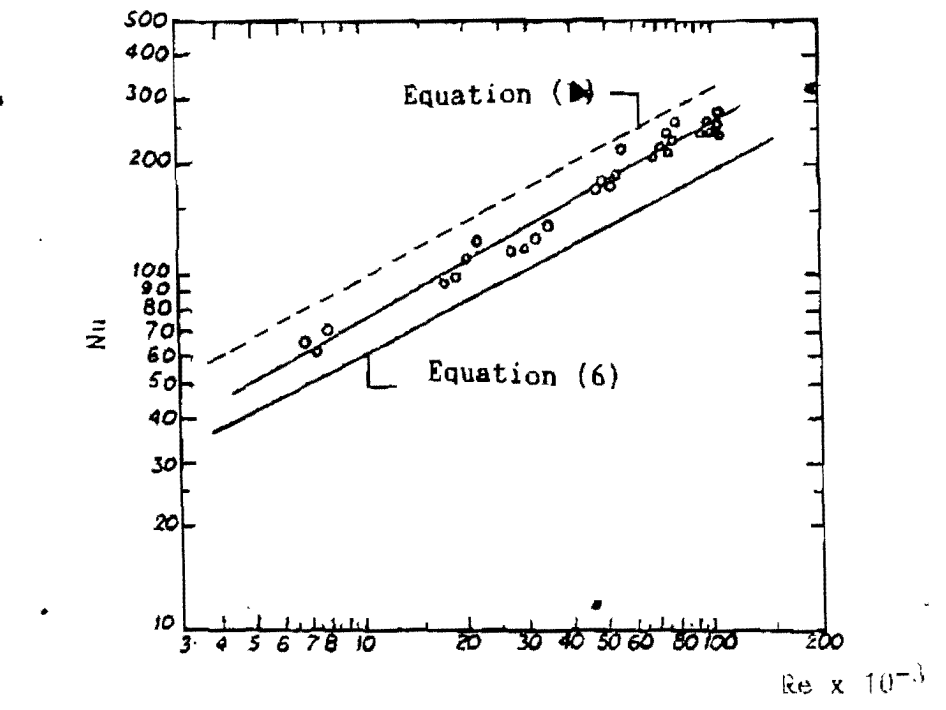

Fig. (5) Average Nusselt number versus Reynolds number. at $x=32.5 \mathrm{~mm}$.

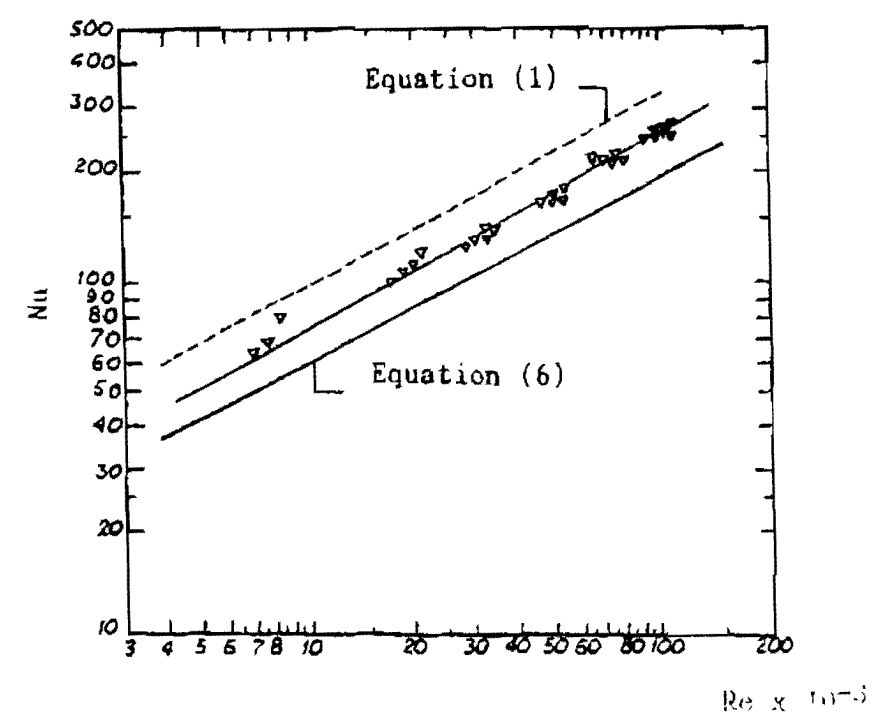

Fig. (6) Iverage Nusselt number versus Reynolds number, at $x=42.5 \mathrm{~mm}$. 


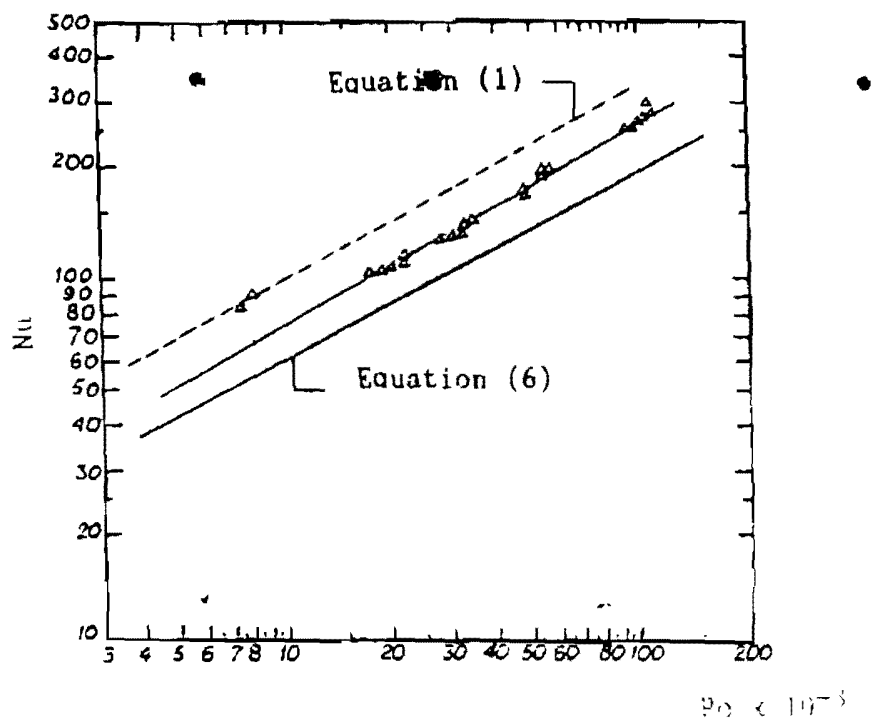

Fig. (7) Average Nusselt number versus Rernolds number, at $x=62.5 \mathrm{~mm}$.

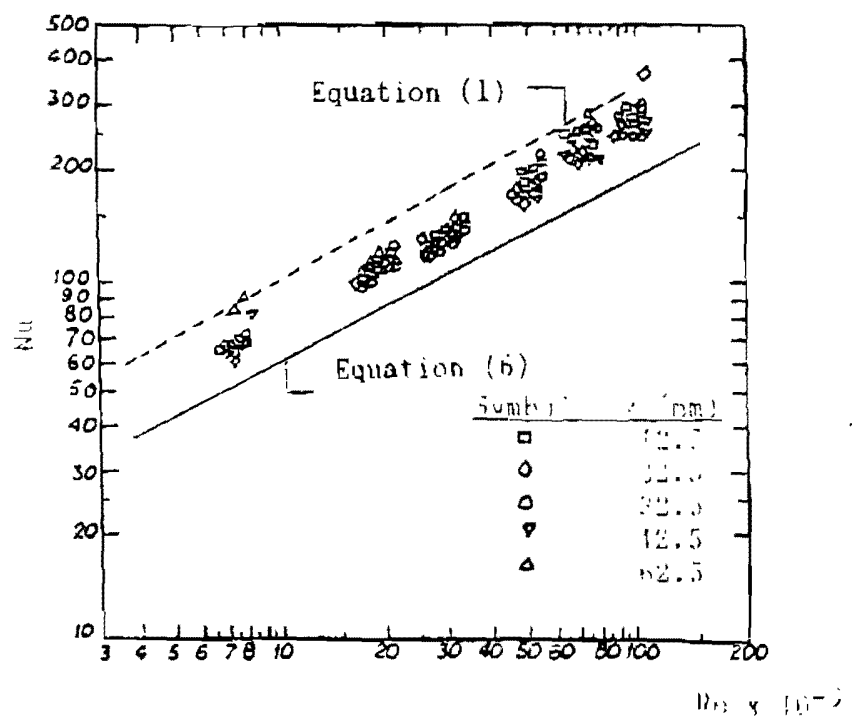

Fig. (8) Average Nusselt number versus Reynulds number. at different locations. 
the course of this work the heat input to the test plate heater varies between 3.70 and $185.5 \%$.

Figure (9) showa Nu values versus $x$ at Re equals 100,000, 50,000, 20,000 and 7,000, One may observed that the Nu alues decrease it the increase of $x, i, e, a s$ the test plate woves toward the channel center. At high Reynolds number the test plate location ( $x$ ) affected more the Nusselt number values than in the case of lower Re values, this bay be bause of the above notation comes frow [18].

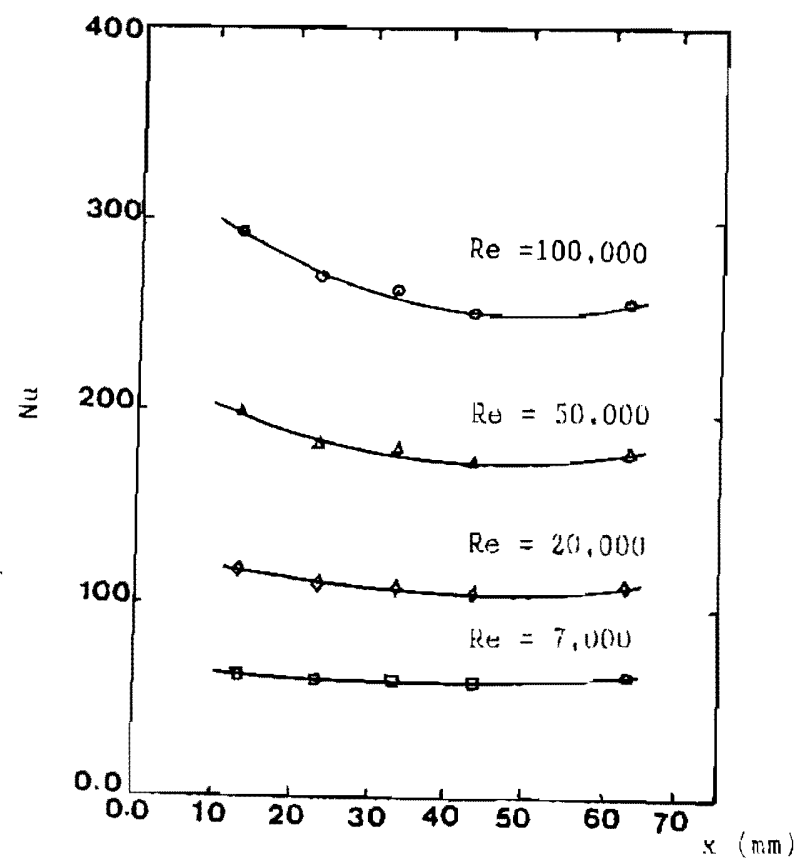

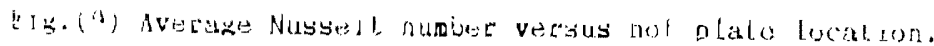

\section{General Heat Transfer Correlation:}

As shown in Fig. (8), the results of the plate locations 12.5 om to 62.5 mo may be taken as one group. A trial was ade to find out a correlation between $\mathrm{N} u$ and $R e$ and the dimensionless distance far from the right wall of the wind tunnel channel $(x=2 x / b)$. The obtained correlation was in the form:

$$
\begin{aligned}
& \mathrm{Nu}=0.573 \times 0.29 \mathrm{Re}^{0.53 x^{-0.055}} \\
& \text { where } \quad 0.2 \leq \mathrm{X} \leq 1.0 \text { and } 6,680 \leq \mathrm{Re} \leq 107,170
\end{aligned}
$$

One may observe that the dimensionless distance $X$ appears in the obtained correlation, i.e. the Nu values depend on the test plate location $(x)$ between the plates array, as previously observed. The experimental data, shown in Fiz. (8), agree with the values obtained from correlation $(7)$ by $\pm 10 \%$. 


\section{CONCLUSIONS}

As a result of the present investixation the following conclusions are derived:

1- is the Reynolds number increaseg the average Nugselt number value increases, i.e., the average heat transfer coefficient increases ith Reynolds number.

2- The obtained correlation indicates that the test olate location between the piates array has a significant effect on the average heat transfer coefficient, specially at high Reynolds number values.

3- The test plate location does not affect much the average heat transfer coefficient, at lor Reynolds number values.

\section{NOSENCLATURE}

The symbols used in the paper have the following meanings:

$A$ = Plate surface area, $\left[\mathrm{m}^{2}\right]$,

$\mathrm{b} \quad=$ ind tunnel channel idth, $[\mathrm{m}]$.

$C_{p}=$ Specific heat of the fluid, $[\mathrm{kJ} / \mathrm{kg} . \mathrm{K}]$

$h \quad=$ Average heat transfer coefficient, $\left[\mathrm{H} / \mathrm{m}^{2} \cdot \mathrm{K}\right]$,

$k=$ Thermal conductivits of the fluid, $[\mathrm{W} / \mathrm{m}, \mathrm{K}]$,

L $\quad=$ Test plate length, $[\mathrm{m}]$,

$\mathrm{Nu}=$ Average Nusselt number, $[h . L / k]$,

Pr $=$ Prandt l number, $[\mu \mathrm{Cp} / \mathrm{k}]$,

$Q_{\text {cond }}=$ Rate of heat lost by conduction, [iV],

Qconv = Rate of heat lost by convection. (it).

$Q_{\text {in }}=$ Power input to the test plate heater. $[\$]$.

Qrad = Rate of heat lost bv radiation. [W].

Re = Reynolds number, [Uav. L/v],

$I_{n}=$ Test plate surface local temperature, [C],

$T_{\mathrm{W}} \quad=$ Test plate surface average temperature, $[C]$,

$\mathrm{T}_{\alpha}=$ Ambient tenperature, $[\mathrm{C}]$.

$u_{\text {av }}=$ Axial avelage velocity component, $[\mathrm{m} / \mathrm{s}]$,

$\mathrm{X}=$ Dimensionless distance from the $r$ ight hand side wall of the wind tunnel channel, $[2 x / b]$,

$x=$ Distance from the right hand side wall of the wind tunnel channel, [ $\mathrm{t}]$,

$\mu \quad=$ Dynamic viscosity of the fluid, [N.s/m $\left./ \mathrm{m}^{2}\right]$,

$v=k^{\prime}$ inematic viscosity of the fluid, $\left[\mathrm{m}^{2} / \mathrm{s}\right]$,

\section{REFERENCES}

1-Shalaby, M. A. "Forced convection heat transfer from a flat plate at differcnt locations", Accepted to be presented in First Engineering Conference- Mansoura, 28-30 yarch (1995).

2-Hwang, U. P. and K. P. Yoran, "Boiling heat trangfer of silicon integrated circuits chip mounted on a substrate". Heat Transfer in Electronic Equipment (edited by M. D. Kelleher and Y. Y. Yovanovich). American Society of Mechanical Enzineers, Ne York (1984).

3-Bar-Cohen, A., and W.Y. Rohsenow, "Thermally optimum spacing of vertical, natural convection cooled, parallel plates", J, Heat Transfer Vol. 106, pp.116-123,(1984). 
4-Bejan, A. "Convection heat transfer", D.157. Problem 11. Hilev, New York (1984); Solution manual for convection heat transfer, pp.9395, Wiley, New York (1984).

5-Sugawara, S., T. Sato, H. Komatsu and H. Osaka, "Effect of free strea. turbulence on flat plate heat transfer", Int. J. Heat Mass Transfer. Vol. 31, No. 1,DD.5-12,(1988).

6-Sparrow. E. M., J. E. Niethammer and A. Chaboki, "Heat transfer and pressure drop characteristics of arravs of rectangular modules encountered in electronic equipuent", Int. J. Heat Mass Transfer, Vol. 25, No.7, pp.961-973,(1982).

7-5parrow, E. M., S. B. Vemur and D. S. Kadle, "Enhanced and local heat transfer, pressure drop, and flow visualization for arrays of block-like electronic components", lnt. J. Heat Mass Transfer, Vol. 26, No. 5. pp. 689-699, (1983).

8-Moffar, R. I., and A. M. Anderson, "Applying heat transfer coefficient data to electronics cooling", ASlr Jr. Heat Transfer, Vol.112, pp.882-890, (1990).

9-Anderson, ג. M., and R. I. Moffar, "Direct air cooline of electronic components: Reducing component temperatures by controlled thermal mixing", Trans. ASME, Vol. 113, Feb.(1991).

10-Shalaby, H. A., F. F. Araid and A. A. Desoky, "Forced convection heat transfer at an inclined and yaved rectangular plate", Mansoura Bulletin Vol. 11, Ho. 1, June (1986).

11-Shalaby, M.A., and F. F. Araid, "Tripping ires effect on heat transfer during wind flow over rectangular inclined and yawed flat plate", M. B., Vol.11, No.2. December(1986).

12-Shalaby, Y.A., and F. F. Araid, "Heat transfer and flow visualization of separated reattached air flow over reversed rectangular flat plate", MEJ Vol.12, No.1, June (1987).

13-Incropera, F. P. "Convection heat transfer in electronic equipment cooling", J. Heat Transfer Vol.110, pp.1097-1111,(1988).

14-Peterson, G. P., and A. Ortega, "Thermal control of electronic equipment and devices", Adv. Heat Transfer, Vol. 20, pp.181$314,(1990)$.

15-Test, F.L., and R. C. Lessmann, "An experimental study of heat transfer during forced convection over a rectangular body", ASME Jr. of Heat Transfer, Vol. 102, DD. 146-151,(1980).

16-Kotmani, D. G., U.N. Gaitonde and S.P. Sukhatme," Heat transfer from rectangular plates inclined at different angles of attack and yaw to an air stream", Jr. of Heat Transfer, Trans. ASME, Vol. 107, p.307, (1985).

17-Holman, J.P., "Heat transfer", McGram-Hill Book Co.. D.232. (1989).

18-kays, W. M., "Convective heat and mass transfer", TATA McGraw-Hill Publishing Company LTD., New Delh, o.58, (1976). 